\title{
The Differences between Art and Design in Italy and China: Definition, Education and Practice
}

\author{
Yeqiu Yang ${ }^{1, a, *}$; DaoJing Wang ${ }^{1, b}$ \\ 1Politecnico di Milano \\ 2Nanjing University of Finance and Economics \\ a10514901@polimi.it ; ${ }^{\mathrm{b}} \mathrm{wdj666@} \mathrm{sina.com.cn}$
}

\begin{abstract}
For a long time, people have never stopped studying the relationship between art and design, the two human spiritual creation activities. The Art emerging for the solution of spiritual forms and the Design for the solution of material functions have always been influencing each other. This article aims at investigating the contribution of the arts to contemporary design in Italy and China, in terms of cultural nurture, design education and design practice. The research focuses on the reflective dimension of the design process. By studying and understanding the art and design, it summarizes a set of the critical research on design and puts forward new methods and theories for the future design culture.
\end{abstract}

Keywords-Art; Design; Creative field; China; Italy

\section{ART AND DESIGN IN THE CHANGING TIMES}

In the "Art history" of thousands of years and the "Design history" of more than one hundred years in the modern sense, the true interplay and interaction between modern design and art should be said to have lasted for only nearly one hundred years: during the period of the industrial revolution and in the early stage of modern design, art and design were differentiated After the industrialization of the modern era was completed, as a beginning, the incorporation of Bauhaus contributed to the unity of art and design. By the time of "postmodernism", art and design reached the greatest degree of integration. Art and design underwent the initial integration and evolved into different fields of specialization. The relationship between design and art is still very subtle despite their new fusion today.
It needs to combine the characteristics of the times to discuss the relationship between art and design. In 1914, the vigorous "Cologne Werkbund Debate "took place in Germany. Hermann Muthesius and Henry van de Velde from Deutseher Wekrbund fiercely debated whether the design should be "standardized" or "artistic". Although there was no winner in the academic debate, the ultimate capitalists and entrepreneurs adopted Muttersius's ideas based on the market conditions at that time. Prof. Silvia Piardi, the dean of the School of Design of Politecnico di Milano has said in the "International Academic Forum on the Future Mission of Art and Design Education", "Globalization has a very interesting embodiment in the project, meaning that the culture and technology can be integrated, but we must also recognize that the cultural tradition needs to be persevered."

\section{DEFINITION OF BOUNDARY BETWEEN THE ART AND THE DESIGN}

In 1979, Prof. Bruce Archer of Royal College of Art published a sensational chart 'relationship in knowledge field' (Figure 1), which described "Design" as a third culture distinct from Humanities and Sciences, the activities closer to design, on the side of Humanities are the Fine Arts, thoes on the side of Sciences are Uesful Arts. However, Scholars, teachers and even design practitioners are used to say that design as a discipline is relatively young, as well as they say that design as a research practice is relatively new (Quoting ken Friendman, 2003).

*This paper work is sponsered by China Scholarship Council. 


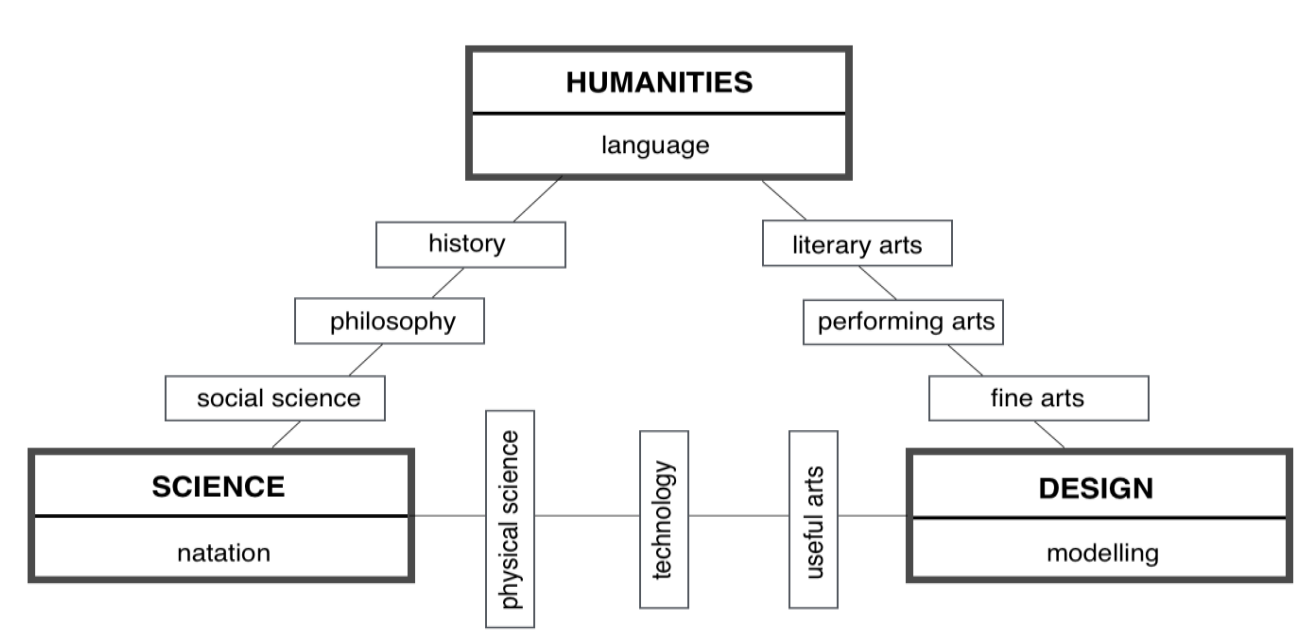

Fig. 1. Chart "relationship in knowledge field"

In China, the word "design" comes from the West, and the concepts of the "design" and "arts and crafts" have been vague for a long time. Historically, China missed two Western industrial revolutions and there even used to be no such concepts as "modernism" and "postmodernism". The concept of "design" was once replaced by the following terms: "decoration", "decorative art", "arts and crafts", "practical art" and "artistic design". At present, people in China still lacks comprehension of the definition of "design", and usually adds the word "artistic" before "design" (Cai Jun, 2002).

However, for Italians, "design" is a kind of culture, art and philosophy, not just creation and practice. In fact, design cannot be simply explained as a discipline or a business activity, but as an integral part of history, providing valuable cultural and technological information as well as philosophy and economics (Andrea Branzi, 2008). The difference between the design and the artwork is that the former must be useful, suitable for human and combined with technical aesthetics, while the latter will not cause practical problems, which is guided by the aesthetic orientation chosen by the artist from time to time (Bruno Munari, 2008).

\section{ART INFLUENCE IN THE DESIGN EDUCATION}

Prof. Hang Jian of China Academy of Art believes that: the School of Design is a new thing. Although Bauhaus and Ulm are short, the design has been hardly accumulated from the perspective of discipline in the entire educational system of the School of Design and in the influence on the human inheritance of design ideas, the design science has been hardly accumulated as a discipline, it is completely open, has no strict construction system, and is still under construction. It seems that there is no sign of completion.

In China, the "design" became a sub-discipline of arts in 2011. From the perspective of discipline, there is an inclusion relationship between the art and the design. According to the ranking of design disciplines by the Ministry of Education of the People' s Republic of China in 2018: Tsinghua University (comprehensive university) and China Academy of Art (fine arts academy) jointly obtained the evaluation of A+. Both two of them have the right to confer doctor degree of design, sharing the first place. There are two different directions in the admission method and training method between the comprehensive universities and art academies: the student who wants to be a student of a comprehensive university must pass many theoretical scientific knowledge examinations, however, the student who wants to be a student of an art academy must possess profound painting skills. In design cultivation studies, the comprehensive universities focus on cultivating students' rational thinking and achieving the comprehensive academic development, however, the students from the art academies should have profound hand painting skills and the academies focus on cultivating the emotional thinking and taking more attempts on visual art design. Simultaneously, the two kinds of graduate designers in different educational backgrounds have different performances in their subsequent works and careers.

In Italy, the boundary between art and design is clear. Historically, the Italian designers often accepted architectural education. They believed that the architects could become designers, and the designers could not become architects. The contemporary Italian design teaching is also existed in the comprehensive universities and fine arts academy. The PHD awarding points in the design science in Italy are only existed in the comprehensive universities currently, and simultaneously, the role of art in the design is also evident in the comprehensive universities and art academies in Italy: the interior design major of Politecnico di Milano has opened a course of "Arts and Languages of the Present", and there are also majors including "Corporate Design" at Accademia di belle Arti di Brera a Milano. 


\section{ARTistic Role IN THE Design PRACTICE}

Both artists and designers follow the challenges of capturing contemporary causes in their own fields, such as products and works in the environment. Their paths describe the tracks that sometimes come together, intertwine, and overlap. In this more obvious case, the existence and differences of the common theoretical and operational terrain become clearer (Luca Guerrini, 2008). There are some differences between the art and the design, howerer, the art is the catalyst and inspiration for activating design (Mazzanti Anna, 2015). "Art" is an expression of consciousness and thinking, and "design" has an obvious tool nature, which is a tool for the method of creating, producing and even expressing the human behaviors. Art and design are connected to each other since occurred and they influence each other. In particular, "design" is a reference to art, which has been already a knowledge to expand the thinking way.

In general, the process of creating artwork begins with a blank canvas. The artwork is derived from the artist's internal opinions or opinions or feelings. They can create art to share this feeling with others, make the audience relate to themselves and then draw experience or get inspired from it. The today's well-known artworks are often those that create the strongest emotional connection between the artist and the audience. In contrast, when the designers start creating new artworks, they almost always have a fixed starting point regardless of information, images, ideas or actions. The designer's job is not to create something new, but to convey something that has already been existed for some purpose. This vision is to inspire the audience to do something: product purchase, service experience, and space use and information interaction. The successful designs are often those projects which can most effectively communicate information and motivate the consumers to implement the design vision.

Calligraphy is a unique Chinese art form, and the design inspiration of Wang $\mathrm{Hao}$ as the winner of the Pritzker Architecture Prize often from calligraphy and painting. The Xiangshan Campus of China Academy of Art is his main representative design artwork, and many forms of his architectural designs come from the traditional Chinese calligraphy and painting art culture (Figure 2). Simultaneously, he has set up a compulsory course in calligraphy art at China Academy of Art. He hopes that the students of China Academy of Art can maintain the traditional Chinese learned temperament and spirit.

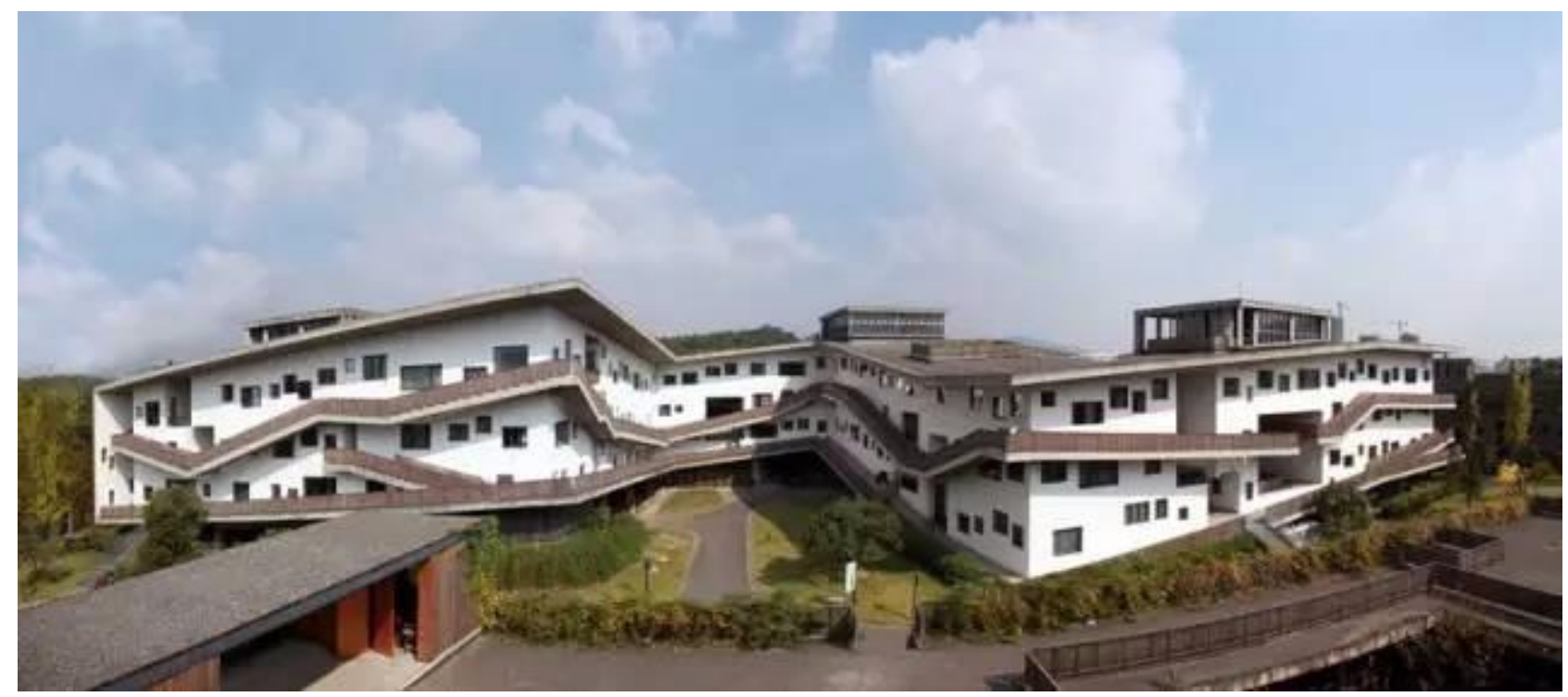

Fig. 2. Xiangshan Campus of China Academy of Art

Fornasetti is a famous decorative art brand in Italy, and its name comes from Piero Fornasetti, the great designer and artist in Milan, who has designed his unique pictorial logo pattern (Figure 3) with the sun, the moon and the face of the female opera actor Lina Cavalieri as the inspiration, and applied them in interior design and product design, his fantastic decorative style has become a fashion trend classic in the home improvement field. 


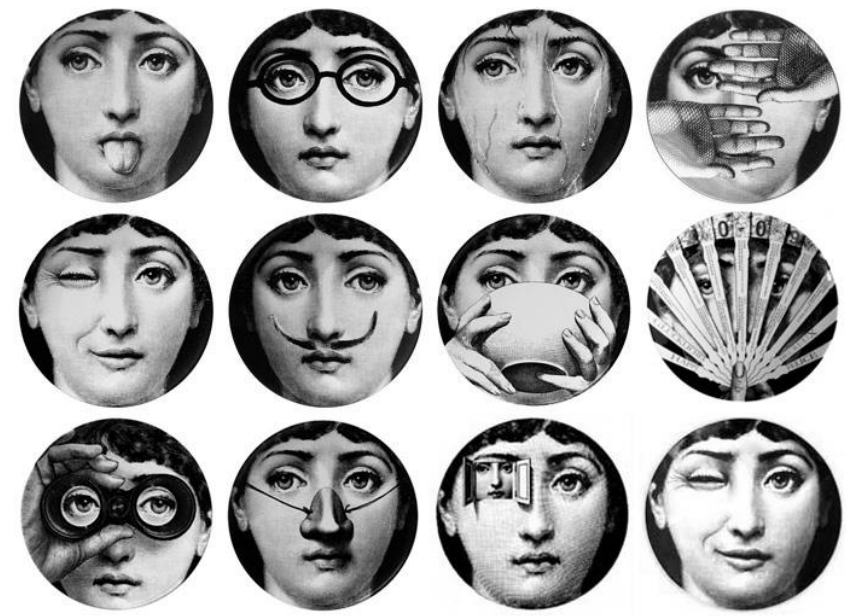

Fig. 3. Pattern Design on Lina Cavalieri

\section{CONCLUSION}

In two different fields, i.e. art and design, as if there are two leads that attract each other, which are sometimes close to each other and sometimes far away from each other, however, the art is more inclined to self-expression and the design is more inclined to serving people. The respective concept and significance of these two creative activities are changed with the changing of times, and trying to specify the constant relationship between design and art is contrary to the true features of things. Both artists and designers follow the challenge of capturing contemporary causes in their respective fields. Their paths are sometimes intertwined together and sometimes overlapped. The design creation involves specific standards, studies, researches as well as rich creativities.

From the creative process, the artist starts to creatively pursue for reaching the final performance with a point of nothingness, the result is accidental, the designer will always create artworks within certain boundaries starting with a set of standards from the concept to completion, and its result is foreseeable. For the creative purpose, both a good artwork and a good design are inspiring. In general, the artist creates his artwork from scratch, and the artwork is deserved from the artist's internal opinions, opinions or feelings. The designers usually motivate people to do something or crate an object: purchase products, obtain services, access to a place or get some information, which are created for the public and the commercial purpose. From the perspective of the audience, the artist can only try to express an opinion or feeling, but it does not mean that the artist's opinions and feelings can only be interpreted in one way. The artwork can be connected with people in different ways because different people have different interpretations. Design is an opposite aspect. If many people believe that there are several explanations for the design, then it can be regarded as a failure for intent ambiguity. The basic intent of the design is to convey information and motivate the audience to do something. Both artists and designers are doing creative artworks and it is a strong artificial argument if trying to regard one discipline more creative than another. There is a clear boundary between them, we must not confuse them and clearly understand their mutual relationships. The author believes that: the designers should not be regarded as artists, nor should artists be required to comply with specific restrictions.

\section{REFERENCES}

[1] Alessi, Chiara. Design senza Designer [M], Roma-Bari: Laterza,2016.

[2] Annicchiarico Silvana, Andrea Branzi eds, Series off Series [M], Mondadori Electa,2009.

[3] Bruno Munari. Design as Art [M], Penguin Classics,2008.

[4] Bruno Munari. Artista e Designer [M], Roma-Bari: Laterza,1971.

[5] Jian, Hang. Design of goodwill [M], Guangxi Normal University Press, 2011.

[6] Jian Hang\& Huiqiu Guo. Chinese Arts \& Crafts: History, Techniques and Legends [M], Beijing: China Intercontinental Press,2009.

[7] Luca Guerrini. Itinerari [M], Maggioli editore,2008.

[8] Lees-Maffei, Grace e Kjetil Fallan, eds. Made in Italy: Rethinking a Century of Italian Design [M], Londra: Bloomsbury,2014.

[9] Michael Sullivan. The Arts of China[M], Shanghai: People's Fine Arts Press, 2014.

[10] Shouzhi,Wang. World History of Modern Design[M], Beijing: China Youth Press,2002.

[11] Shouzhi,Wang. World History of Contemporary Art [M], Beijing: China Youth Press, 2002.

[12] Sparke, Penny. Italian Design: 1870 to the Present [M],Thames \& Hudson, 1988

[13] Hu,Wang \& Ping,Xu eds. Chinese design works[M],Beijing: The Commercial Press, 2012.

[14] Hong,Wu. Ruins of the story : Chinese art and visual culture in the presence and absence [M], Shanghai: People's Publishing House,2012.

[15] Yu, Shen. China Concept Design History [M],Shanghai: People's Publishing House, 2017.

[16] Yu, Shen. 1949-1979 China Industrial Design Collections [M], Shanghai: People's Publishing House, 2014. 